\title{
(Autonomia do) Direito e desacordos morais
}

\author{
(Autonomy of) Law and moral disagree- \\ ment
}

Lenio Luiz Streck ${ }^{1}$

Gilberto Morbach ${ }^{2}$

\begin{abstract}
Resumo: "Ações afirmativas são justas ou injustas?" "O aborto deve ser permitido ou proibido?" “O Estado deve intervir no que diz respeito à distribuição de renda?"; são muitas as perguntas que ilustram nossos constantes desacordos morais. Em sociedades (cada vez mais) fragmentadas e plurais, é natural que agentes com as mais diversas concepções acerca de conceitos, definições e proposições morais discordem entre si. Partindo desse pressuposto, e, através de uma
\end{abstract}

1 Doutor em Direito pela Universidade Federal de Santa Catarina (UFSC), com pós-doutorado em Direito pela Faculdade de Direito da Universidade de Lisboa (FDUL). Professor Titular da Universidade do Vale do Rio dos Sinos (Unisinos/RS) e da Universidade Estácio de Sá (UNESA/RJ) e Professor Visitante da Universidade Javeriana de Bogotá, da Universidade de Málaga e da Universidade de Lisboa.

2 Mestrando em Direito Público, como bolsista do Conselho Nacional de Desenvolvimento Científico e Tecnológico (CNPq), pela Universidade do Vale do Rio dos Sinos (Unisinos/RS). Bacharel em Direito pela Universidade Feevale/RS. Membro do Dasein - Núcleo de Estudos Hermenêuticos e da Associação Brasileira de Direito Processual (ABDPro). 
revisão bibliográfica sob o "método" fenomenológico-hermenêutico, tomando como base uma releitura (i) do diagnóstico de Alasdair MacIntyre quanto à natureza dos desacordos morais e (ii) das diferentes respostas de Ronald Dworkin e Jeremy Waldron com relação ao papel do Direito nesse cenário, o presente ensaio pretende investigar (i) em que medida os insights de MacIntyre acerca da filosofia moral podem também servir à filosofia jurídica e, com isso, (ii) qual é, de fato, o papel do Direito em face dos desacordos. A pesquisa aponta à ideia de que tanto a busca por uma resolução democrática dos desacordos quanto a melhor interpretação de nossa prática jurídica exigem um elevado grau de autonomia do Direito.

Palavras-chave: Desacordos. Democracia. Crítica Hermenêutica do Direito.

Abstract: "Are affirmative action policies just or unjust?" "Should abortion be legal or illegal?" "What is the role of the state on the distribution of wealth?" Several questions could illustrate our constant moral disagreements. In (increasingly) plural, fragmented societies, it is only natural that agents with diverse conceptions regarding moral concepts and propositions disagree among each other. This essay, therefore, under the hermeneutical-phenomenological "method", first, reinterprets (i) Alasdair MacIntyre's comments on the nature of moral disagreement and (ii) Ronald Dworkin's and Jeremy Waldron's different answers on the role of law concerning these disputes. Then it seeks to investigate (i) whether MacIntyre's insights are applicable to jurisprudence and (ii) what is the best account of how law relates to moral disagreement. Our conclusions point to the idea that both a search for a democratic solution to moral disagreements and the best interpretation of our legal practice demand a high level of autonomy of law itself. 
Keywords: Disagreement. Democracy. Hermeneutical Critique of Law.

\section{Introdução}

Se há poucos consensos em sociedade, paradoxalmente, um deles é precisamente o fato de que discordamos entre nós mesmos. Somos muitos e são muitos nossos desacordos. "Não discordamos apenas sobre a existência de Deus e o sentido da vida", diz Jeremy Waldron; "discordamos também sobre o que conta como termos justos de cooperação entre pessoas que discordam sobre a existência de Deus e o sentido da vida". ${ }^{3}$ Discordamos, portanto, sobre justiça e sobre moralidade política. Isso significa dizer que nossos desacordos não se dão somente com relação a questões que dizem respeito a nós mesmos e ninguém mais. Nossas divergências relacionamse também com aquilo que corresponde à melhor maneira de resolver essas divergências próprias, especialmente em sociedades formadas por cidadãos que sustentam diferentes perspectivas e concepções de justiça, de moralidade, do bom, do justo, do certo.

Não é sem razão que essa questão tem ocupado os filósofos morais e políticos: em comunidades cada vez mais plurais e fragmentadas, os desacordos tendem a crescer na mesma medida em que se acirram. Há desacordos entre conservadores e progressistas; há desacordos entre socialistas e adeptos do laissez-faire. Movimentos feministas defendem o direito ao aborto, cristãos tradicionais tendem a rejeitá-lo em favor do direito à vida do feto. E a lista segue ad infinitum, uma vez que novos desacordos surgirão antes que se termine de listar todos aqueles que já existiam. Naturalmente, não

3 WALDRON, 1999, p. 01. 
se pretende, neste ensaio, encerrar a questão da natureza e do status por trás desses juízos práticos; séculos de filosofia moral não o fizeram. Inúmeros livros, tratados, teorias, autores e escolas, todos enfrentaram e enfrentam até hoje os pressupostos metafísicos, epistemológicos, psicológicos e semânticos que subjazem às proposições morais. Nossa pretensão é um tanto mais mais modesta - mas não menos importante.

Não é menos importante porque volta seu olhar a um aspecto indispensável à nossa vida prática. Para além daquele que inaugura estas linhas, outro dos poucos consensos que podemos observar é o de que, diante de tantos desacordos profundos, uma convivência pacífica exige uma instância que os regule. Se temos diferentes concepções sobre os conceitos que fazem parte de quem somos e como vivemos, sociedades modernas exigem instituições competentes e aptas a determinar princípios mínimos comuns que ditem nossos rumos político e social, garantindo, ao menos, a coexistência desses indivíduos e grupos, em toda sua diversidade e multiplicidade de crenças e convicções. Em uma sociedade democrática contemporânea - justamente na medida em que "a democracia contemporânea de sociedades plurais" é exatamente "caracterizada pela existência de conflitos"4 - , também parece inegável que o Direito assuma especial relevância nesse cenário.

A tarefa que se coloca, portanto, é a de enfrentar as complexas circunstâncias políticas de uma sociedade em desacordos tão profundos quanto constantes, buscando oferecer a melhor interpretação do Direito enquanto instância responsável por organizar essa comunidade política em toda sua multiplicidade. Assim, diante disso, este ensaio, está estruturado da seguinte maneira: inicialmente, (i)

4 Cf. BAHIA, NUNES, 2010. 
buscamos uma breve exposição do diagnóstico de Alasdair MacIntyre sobre a natureza dos desacordos morais. Depois, (ii) refletimos sobre o papel do Direito enquanto esfera responsável por regular esses desacordos, trazendo as propostas interpretativas de Ronald Dworkin e Jeremy Waldron acerca do exercício, das possibilidades e dos limites dessa atribuição. Por fim, (iii) oferecemos uma releitura tanto do diagnóstico de MacIntyre - aproximando seus insights sobre filosofia moral das concepções dominantes em nossa prática jurídica - quanto das teorias de Dworkin e Waldron - abordando-as de forma crítica - , e (iv) expomos aquela que nos parece ser a melhor interpretação do fenômeno jurídico como resolução dos desacordos de forma adequada ao contexto brasileiro, defendendo a autonomia do Direito e a necessidade de uma teoria da decisão.

\section{Desacordos morais, o Movimento Know-Nothing e o emotivismo}

Alasdair MacIntyre, filósofo escocês, diz que o que mais chama atenção nos enunciados morais contemporâneos é o fato de que esse tipo de proposição é utilizado precisamente para expressar desacordos. Por sua vez, o que mais chama atenção nos debates nos quais esses desacordos são expostos é seu caráter interminável - não apenas no sentido de que seguem "on and on and on" (embora o filósofo reconheça ser também esse o caso), mas também pelo fato de que, aparentemente, não se encontra qualquer termo possível nesses debates; isto é, "parece não haver qualquer meio racional pelo qual se possa assegurar um acordo moral em nossa cultura".${ }^{5}$ Basicamente, MacIntyre quer dizer, para além da óbvia constatação de que vivemos em uma sociedade de

5 MACINTYRE, 2007, p. 08. 
desacordos, que vivemos em um tempo no qual não parece haver qualquer critério último capaz de resolver o debate do ponto de vista argumentativo; e a explicação para isso reside, ainda segundo MacIntyre, na hipótese de que a linguagem moral passa por um estado de desordem.

MacIntyre abre After Virtue, sua magnum opus, ilustrando esse que seria seu ponto a partir de uma metáfora "perturbadora" ("a disquieting suggestion"): 6 ele pede que imaginemos, hipoteticamente, um cenário absolutamente catastrófico nas ciências naturais, no qual a população em geral passa a culpar os cientistas por uma série de desastres naturais. Essa responsabilização acaba por gerar uma série de revoltas populares - laboratórios são queimados, físicos são linchados, livros são queimados. Mais do que isso, as revoltas acabam por levar ao poder um movimento político chamado Know-Nothing (algo que poderia ser traduzido como "Saber-Nenhum", "Nada-Saber"), que, além de proibir o ensino científico nas escolas e universidades, prende e executa os cientistas que ainda exerçam a função.

Algum tempo depois, há uma reação contra o KnowNothing: um grupo de pessoas pretende trazer a ciência de volta à tona. O problema é que esse grupo, embora iluminado, esqueceu grande parte do que a ciência realmente era; havia como ser diferente? Tudo que eles ainda tinham consigo era nada mais que "fragmentos": um certo "conhecimento sobre alguns experimentos do passado", mas completamente "apartado de qualquer conhecimento acerca do contexto teórico que a eles conferia significado"; "meios capítulos de livros"; " páginas individuais de alguns artigos, nem sempre legíveis"; enfim, fragmentos, e nada além disso. Esse saber, embora fragmentado, passou a ser reutilizado em práticas

6 A metáfora que será aqui explanada está no capítulo inicial de After Virtue. Cf. MACINTYRE, 2007, pp. 01-07. 
que levavam nomes como "física", "química" e "biologia". A partir desses novos-velhos, velhos-novos tópicos, ressignificados a partir dos fragmentos, "adultos discutiam entre si acerca dos méritos da teoria da relatividade, teoria da evolução, teoria da combustão", "possuindo apenas um conhecimento muito parcial sobre cada uma delas". Crianças aprendiame "decoravam as parcelas sobreviventes da tabela periódica", e "recitavam como palavras mágicas alguns dos teoremas de Euclides". O problema? "Ninguém, ou quase ninguém, percebia que aquilo que se fazia não era, de forma alguma, ciência natural em qualquer sentido autêntico" ${ }^{7}$

Nessas hipotéticas (e catastróficas) circunstâncias de um saber fragmentado - que era o saber disponível - , os cidadãos "utilizam expressões como 'neutrino', 'massa', 'gravidade específica',' massa atômica', de modo sistemático e, geralmente, inter-relacionado", de um modo que, em algum sentido, "em maior ou menor grau", "parecia-se com os meios pelos quais tais expressões eram empregadas e utilizadas antes que o conhecimento científico tivesse sido tão grandiosamente perdido". Ainda assim, "muitas das crenças outrora pressupostas pelo uso dessas expressões foram perdidas", de modo que, no cenário do saber fragmentado, havia um "elemento de arbitrariedade e até de escolha em sua aplicação" que pareceria, a nós, muito surpreendente. "Premissas aparentemente rivais e antagônicas pelas quais nenhum tipo de argumento seria possível tornar-se-iam abundantes", de modo que "teorias subjetivistas da ciência surgiriam", 8 e seriam "criticadas por aqueles que sustentavam que a noção de verdade subjacente àquilo que tomavam como ciência era incompatível com o subjetivismo". ${ }^{9}$

7 MACINTYRE, 2007, p. 01.

8 Grifo nosso.

9 Grifo nosso. MACINTYRE, 2007, p. 02. 
Avancemos a partir da pergunta colocada pelo próprio MacIntyre: qual seria a justificativa para construir hipoteticamente esse mundo distópico, em "grave estado de desordem", similar àquele que "alguns autores de ficção científica já construíram"? O próprio autor responde, sustentando que a hipótese que planeja desenvolver é a de que "no mundo real, que habitamos, a linguagem moral está no mesmo estado de grave desordem que aquele pelo qual passava a linguagem da ciência natural no mundo imaginário que descrevi" ${ }^{10}$ Tudo o que temos hoje, para MacIntyre, são nada mais que "fragmentos de um sistema conceitual, partes que agora carecem dos contextos dos quais seus significados originalmente derivam"; temos "simulacra"11 da moralidade, utilizamos muitas de seus conceitos centrais, mas "perdemos - em grande parte, senão completamente - nossa compreensão, prática e teórica, da moralidade" ${ }^{12}$

Se os conceitos de massa, gravidade, etc., eram utilizados de forma fragmentária - e, portanto, afastados de seus sentidos originais (e autênticos) - na distopia das ciências naturais, MacIntyre diz que é exatamente isso que ocorre, de fato, com relação aos conceitos próprios da linguagem moral em nosso debate moral contemporâneo: conceitos como "virtude", "justiça", "dever", todos tornaram-se outra coisa, com um significado distinto daquele que se identificava na variedade de contextos em que se originavam. "Kant deixa de ser parte da história da Prússia", "Hume já não é mais um escocês": tratamos "Platão e Hume e Mill" como contemporâneos um do outro e de nós próprios, abstraímos suas obras de seu contexto cultural e social e conferimos a elas uma falsa independência. ${ }^{13}$

10 Grifo nosso. MACINTYRE, 2007, p. 02.

11 Nota de tradução: plural de simulacrum, (nada mais que) representação que transmite determinado objeto (ou conceito) como autêntico, genuíno. "Simulacro".

12 Grifo nosso. MACINTYRE, 2007, pp. 02-03.

13 MACINTYRE, 2007, pp. 12-13. 
Esse (ainda) não é o diagnóstico (completo) oferecido por MacIntyre; é, em verdade, uma das causas e um dos sintomas que nos remete ao diagnóstico per se: o debate moral contemporâneo tem, segundo MacIntyre sido dominado pelo emotivismo, "a doutrina segundo a qual juízos valorativos" - ou, mais especificamente, "todos os juízos morais" "são nada mais que expressões de preferência, de atitude, de sentimentos, na medida em que tenham caráter moral ou valorativo".${ }^{14}$ A partir de uma postura emotivista, há uma distinção entre (i) juízos factuais - que, porque pertencentes à esfera dos fatos, são passíveis de verificação, e (ii) juízos morais - que, porque nada mais que expressões de atitudes e/ou sentimentos, não podem ser verdadeiros ou falsos. Nenhum método racional seria capa de assegurar um consenso moral porque não há um. Se o emotivismo está correto, os desacordos morais são racionalmente intermináveis.

O emotivismo foi desenvolvido ao longo da tradição metaética em diferentes versões, algumas mais, outras menos sofisticadas. Para A. J. Ayer, por exemplo, proposições morais em nada diferir-se-iam de outras expressões meramente emocionais; juízos éticos ou estéticos não seriam, pois, passíveis de verificação, uma vez que completamente subjetivos. ${ }^{15}$ Para Richard Hare, esses juízos, embora subjetivos, têm uma pretensão de universalização, de modo que os juízos morais expressariam um tipo de comando generalizado - aqui, pois, uma explicação sintetizada daquilo que, em metaética, viria a ser chamado de prescritivismo. ${ }^{16}$ A explicação de Hare é mais sofisticada, mas é tão cética quanto a de Ayer: pretensão de prescrição universal à parte, o juízo ainda assim não é candidato à verdade ou falsidade. Dworkin classifica o emotivismo

14 MACINTYRE, 2007, p. 13.

15 Cf. AYER, 1990.

16 Cf. HARE, 1952. 
como uma espécie de "status skepticism"17 - que é um tipo de ceticismo externo (por ter a pretensão de estar situado fora da moralidade) - porque, assim como outras teorias céticas, o emotivismo nega aos juízos morais o status factual: exatamente por fazer, como vimos, uma distinção afiada entre fato e valor (entre "is" e "ought"), o emotivista dirá que é um erro acreditar que proposições morais possam descrever algo. Assim, do fato de que juízos morais não descrevem algo natural, presente, observável e verificável no mundo, o emotivista deriva que não se pode tratar da moralidade a não ser como se esta fosse a expressão de uma emoção ou de um comando. ${ }^{18}$ É nesse sentido que Arthur Ferreira Neto bem explica e exemplifica: de acordo com o emotivismo, "um ato de fala dotado de contornos morais nunca se refere a nada, a não ser a uma emoção ou a um sentimento do emissor desse ato de fala"; essa é, portanto, uma postura que "leva a sério a premissa de que não há qualquer sentido objetivo no ato de fala que reporta expressões como 'certo' ou 'errado', 'bom' ou 'mau'". ${ }^{19}$

Frise-se: "não há qualquer sentido objetivo no ato de fala que reporta expressões como [...] 'bom'”. É aqui que se torna bastante clara a origem esse diagnóstico - de uma, digamos, hegemonia emotivista no campo do discurso moral - de que fala MacIntyre: a indefinibilidade do conceito de bem, ${ }^{20}$ propugnada por G. E. Moore em seu Principia Ethica, de 1903. ${ }^{21}{ }^{22}$ Para Moore, qualquer tentativa de definição acerca do

17 Em tradução livre, "ceticismo com relação ao status".

18 Cf. DWORKIN, 2011, p. 32.

19 FERREIRA NETO 2015, p. 161.

20 "Bem", por vezes traduzido como "bom". O conceito é do inglês "good", e, daqui para diante, ambas traduções serão utilizadas intercambiavelmente, de modo que melhor adeque-se ao contexto.

21 Para este artigo, utilizou-se a edição revisada de 2002 da Cambridge University Press. Cf. MOORE, 2002.

22 Moore diz que, antes dele, somente Sidgwick (o célebre utilitarista) havia 
bem em termos de propriedades como "prazer", "interesse", "felicidade", está fadada ao fracasso. Isso porque ainda que todas as coisas que gerem "felicidade", "prazer", enfim, ainda assim a palavra "bem/bom" não significaria "prazeroso". O ponto é: a assertiva "bom significa algo que desejamos" não é uma assertiva verdadeira por definição. Esse é o famoso open question argument (traduzido livremente como "argumento da questão em aberto" ${ }^{23}$ de Moore, que expressa de forma sintetizada seu argumento da falácia naturalista: ${ }^{24} \mathrm{o}$ bem/ bom - o conceito de bem/bom - não é reduzível a qualquer propriedade natural. De qualquer característica natural de $x$ não se deriva que $x$ seja bom. Para Moore, portanto (ainda que o autor refira-se especificamente ao conceito do bem), qualquer conclusão valorativa exige ao menos uma premissa igualmente valorativa, não sendo possível derivar um dever ser ("ought") de um ser ("is"). ${ }^{25}$ Moore, nesse sentido, teorizou, de forma paradigmática, o argumento que, enfim, fazia uma contraposição muito direta a um período no qual "os valores humanos [...] eram tidos como ingredientes do universo a serem encontrados no cosmo". Dizer que uma coisa era boa ou má, certa ou errada, era tido como uma ação descritiva, uma vez que registraria que as coisas em questão tinham essas propriedades intrinsecamente. Nonsense, para Moore.

Esse argumento, como visto, é aceito integralmente pela postura emotivista. Como vimos, um adepto do emotivismo - como Moore - distingue os juízos factuais dos juízos morais. A diferença é que, para aquele, repetimos, disso segue-se que os juízos morais não podem ser verdadeiros ou

classificado o conceito como indefinível: "so far as I know, there is only one ethical writer, Prof. Henry Sidgwick, who has clearly recognised and stated this fact". MOORE, 2002, p. 69.

23 Cf. MOORE, 2002, pp. 63-70.

24 Cf. MOORE, 2002, pp. 90-91.

25 Para além do próprio autor, aqui referenciado, boas análises em BALDWIN, 2010; RIDGE, 2018. 
falsos; somente os juízos factuais são passíveis de verificação. Não é isso que Moore diz, mas é isso que o emotivismo tira de suas conclusões. Daí o motivo para nosso (aparente) desvio ao tratarmos de MacIntyre.

Para o escocês, se Moore teria acertado em sua refutação às teorias éticas que se fundamentam a partir de fatos naturais para estabelecer a esfera da moralidade, ficamos sem qualquer fundamento. Desse modo, ações justificadas a partir daquilo que seriam verdadeiras ficções - como "direitos naturais", "os ditames da razão", "o princípio da utilidade" - têm sido nada mais que a expressão de meras preferências pessoais disfarçadas de asserções de princípios. E essa característica, que MacIntyre diz ser, é verdade, predominante em nossa cultura, é tomada pelo emotivismo como universalmente verdadeira. Eis, então, a diferença entre a hipótese de MacIntyre e a metaética emotivista: para aquela, a expressão de meras escolhas e inclinações através de justificativas fictícias é uma característica típica do discurso moral em nosso tempo; para esta, essa seria, em verdade, uma característica típica do discurso moral per se, ponto final.

Dito de outro modo: para o emotivismo, qualquer tentativa, passada ou presente, de justificação racional que sustente uma moralidade objetiva falha porque não é possível justificar racionalmente um juízo moral; um juízo que é nada mais que a expressão de uma atitude, uma preferência; algo subjetivo. Para MacIntyre, essa é somente a percepção que domina nossos tempos; é tão dominante, contudo, quanto equivocada. MacIntyre diz que há, sim, objetividade e autoridade na esfera moral; contudo, essa autoridade está em uma moralidade que foi perdida, tal como o saber autêntico teria sido em sua distopia do movimento Know-Nothing. $\mathrm{O}$ emotivismo não é verdadeiro, mas os indivíduos de nossa época falam e agem como se fosse; o emotivismo, portanto, 
é a postura que domina nossa cultura moral, que, por isso mesmo, está baseada em um equívoco. ${ }^{26}$

\section{Direito e desacordos}

Seja como for, tenha uma perspectiva emotivista ${ }^{27}$ dominado nosso discurso moral contemporâneo ou não, ${ }^{28}$ parece inegável que os desacordos morais atuais são (ou, no mínimo, parecem ser) intermináveis. Tenham eles um caráter primordialmente político, social ou econômico, a moralidade está sempre subjacente, e são inúmeras as concepções do bem em sociedades cada vez mais fragmentadas, dentro das quais há indivíduos e coletividades solidárias às mais distintas crenças metafísicas e aos mais variados costumes (que remontam às mais diferentes tradições). Só que essas sociedades, esses indivíduos, essas coletividades estão condenadas a conviver mutuamente, com todas suas diferenças. Daí a importância de uma instância capaz de promover, senão o acordo, ao menos uma resposta que solucione $e^{29}$ o conflito, politicamente falando. Liberais vão discordar de socialistas, assim como conservadores dificilmente concordariam com progressistas, especialmente quando as eventuais pautas em disputa guardam relação direta com suas convicções mais opostas entre si; isso é legítimo. É precisamente por isso que

26 MACINTYRE, 2007, p. 25.

27 Frise-se, no, e apenas no, sentido de uma aceitação ordinária, como se o emotivismo fosse verdadeiro.

28 Parece-nos ser o caso. Acompanhamos o diagnóstico de MacIntyre, ao não constatarmos nenhuma epistemologia adequada por trás dos pretensos fundamentos das mais frequentemente externadas proposições morais cotidianas.

29 O melhor termo aqui seria, do inglês, "settlement", que parece expressar aquilo que queremos dizer, com uma fidelidade um pouco maior que as traduções do vocábulo (solução, resolução, acordo). 
instituições políticas são dotadas da autoridade para dispor, autoritativa e finalmente, sobre as questões que nos dividem. Como diz Waldron, “" n]ão se trata de encerrar a questão nada pode fazê-lo - , mas de estabelecer uma base comum de ação quando a ação é necessária" ${ }^{30}$

Daí a importância do Direito. Os desacordos de que falamos não se dão em um hipotético estado de natureza, mas em sociedades como a nossa: com instituições e sistemas político e jurídicos bem definidos. Não se trata apenas de legislar, mas de aplicar, reforçar e interpretar as normas legais. Só que as coisas, novamente, não são assim tão simples - alguém pensava que seria diferente? Se é possível concordar que (i) uma coexistência pacífica exige uma instância que regule nossos desacordos profundos, e que (ii) o Direito tem uma importante função institucional nesse sentido, haverá desacordos sobre uma série de outras questões que se colocam a partir dessas premissas. Em que medida as instituições estão, de fato, autorizadas a interferir justamente em nossa autonomia? Como o Direito deve lidar com a resolução desses desacordos? Há limites para a atuação judicial? Quais são esses limites?

Essas perguntas surgem por uma questão lógica. Afinal, se é verdade que concordamos com a ideia de que o Direito é um sistema apto a regular nossas condutas - e parecenos que é - , também é verdade que a prática jurídica é, na definição de Dworkin, "argumentativa" 31 por essência. O que é o Direito? A pergunta que, prima facie, parece elementar, é, em verdade, de difícil resposta. Atribuir significado ao Direito não se trata apenas de identificar o que compõe

30 Tradução livre para "[w] need settlement not so much to dispose of the issuenothing can do that-but to provide a basis for common action when action is necessary". WALDRON, 2009b, pp. 1346-1406.

31 DWORKIN, 1986, p. 13. 
aquilo a que chamamos de material jurídico de um ponto de vista factual; é também uma questão de "argumentar a partir desses materiais, de argumentar sobre sua interpretação e sobre os princípios gerais que eles, ao menos em tese, pressupõem". ${ }^{32}$ Acompanhamos Dworkin quando este diz que o Direito é um fenômeno interpretativo, e é por isso que haverá uma série de diferentes respostas sobre qual seria a melhor concepção daquele que consideramos ser um "acordo pré-interpretativo" possível sobre o Direito: uma prática que regula a conduta daqueles que, compondo uma comunidade política, divergem profunda e fundamentalmente entre si sobre muitos dos mais básicos aspectos de nossas vidas. ${ }^{33}$

Além de Dworkin, Jeremy Waldron - mais um de seus alunos que viriam a se tornar, como o mestre, importantes juristas no cenário da jurisprudence ${ }^{34}$ anglo-saxônica é outro autor que sustenta ser o Direito uma prática interpretativa. "Sinto-me”, diz Waldron, "profundamente influenciado pela obra de Dworkin acerca dos desacordos teóricos no Direito" ${ }^{35}$ Para Waldron, o Direito é uma prática essencialmente argumentativa. Nossos desacordos sobre, digamos, nosso sistema tributário não se encerram em uma lei que o organize; eles também se dão quando discutimos o sentido autêntico por trás da norma, a melhor interpretação do significado subjacente à diretriz legislativa. É precisamente por isso que não basta definir o Direito com uma das instâncias responsáveis por regular nossos desacordos; é

32 WALDRON, 2004, pp. 319-336.

33 Para as considerações de Dworkin sobre o Direito enquanto fenômeno interpretativo, e sobre "acordo pré-interpretativo", conceitos e concepções, ver, sobretudo, a seção Concepts and Conceptions of Law, em DWORKIN, 1986, pp. 90-108.

34 "Teoria do Direito", em tradução livre.

35 "I am strongly influenced by Dworkin's work on theoretical disagreement in law". WALDRON, 2012, pp. 01-32. 
necessário também que se diga como.

Se é verdade que Dworkin e Waldron concordam tanto com relação ao papel que o Direito preenche nesse sentido quanto com relação à sua natureza interpretativa e argumentativa, também é verdade que ambos discordam com relação a algumas das perguntas que surgem a partir desse acordo inicial. Cada um deles, portanto, responde de forma diferente à pergunta que poderíamos elaborar como “qual é o papel dos legisladores, dos juízes e das Cortes nisso a que chamamos 'Direito' e conferimos a competência de resolver nossos desacordos?". Tomemos essas respostas como ponto de partida, de modo a expor, em brevíssimas sínteses, os principais pontos de cada uma delas.

\section{Ronald Dworkin}

Há uma opinião corrente, muito popular - e, para Dworkin, ela é tão popular quanto inverossímil ${ }^{36}$ - , segundo a qual, as convicções políticas (entendidas em sentido lato) dos juízes e cidadãos em geral acerca do conteúdo do Direito não deve ter qualquer relevância, não deve interferir em nenhuma medida, no momento de sua aplicação. É uma concepção segundo a qual Direito e política são duas esferas completamente separadas uma da outra. A opinião contrária também é popular: a de que é tudo, afinal, uma questão política, e que, em seus votos, os juízes fazem nada mais que expressar suas próprias conviç̧ões pessoais como se fossem legisladores. Dworkin rejeita as duas abordagens, sustentando que, ao passo em que há uma conexão necessária entre Direito e moralidade política, ${ }^{37}$ também é verdade

36 DWORKIN, 1985, p. 02.

37 Mais tardiamente em sua obra, Dworkin chega a classificar o Direito como um ramo da moralidade política. Cf. DWORKIN, 2011, p. 05. 
que a própria natureza do Direito - a própria ideia de responsabilidade política que cabe àqueles que compõem a comunidade jurídica em uma democracia - exige que os juízes considerem, em meio ao raciocínio judicial, apenas aquelas de suas convicções de moralidade política que acreditem, de boa-fé, fazerem parte de uma interpretação geral coerente da cultura jurídica e política da comunidade em questão. ${ }^{38}$

Dworkin, rejeita, portanto, ao mesmo tempo, tanto a ideia de um Direito cindido da política e da moral quanto a ideia de que os juízes não se diferem de outros officials ${ }^{39}$ responsáveis pela tomada de decisões. É precisamente nesse sentido que, em contraste com a visão tipicamente associada ao positivismo jurídico, ${ }^{40}$ Dworkin compreende que, em casos difíceis - casos em que a compreensão ordinária diz não haver Direito aplicável - os juízes não estão desvinculados para agir com discricionariedade; estão adstritos aos princípios de moralidade política e às decisões políticas e jurídicas precedentes. ${ }^{41}$ Em meio a isso, Dworkin difere argumentos de política - cuja natureza é autoevidente - e argumentos de princípio, que são justamente os argumentos que fundamentam uma decisão tomada não a partir de cálculos utilitários (ou mesmo propriamente políticos per se), mas a partir de uma exigência das noções

38 "Judges should enforce only political convictions that they believe, in good faith, can figure in a coherent general interpretation of the legal and political culture of the community". DWORKIN, 1985, p. 02.

39 O termo é frequentemente traduzido como "funcionários". Na literatura jurídica anglo-saxônica, é utilizado de modo a representar todos aqueles que compõem a prática político-judiciária, a produção e aplicação legislativa, o reforço no cumprimento das leis, etc.

40 Para críticas ao paradigma juspositivista, a partir da hermenêutica filosófica de matriz gadameriana, ver STRECK, 2004, e STRECK, 2008, em publicações na Revista Brasileira de Estudos Políticos.

41 Cf. DWORKIN, 1978, pp. 14-45. 
de justiça que se adequem à moralidade institucionalizada.

Essa inflexão tem sua raison d'être no seguinte sentido: com essas reflexões, Dworkin enfrenta questões muito próprias no que dizem respeito à resolução dos desacordos morais de que tratamos aqui. Em uma democracia, a resolução desses desacordos deve ser tomada (i) com base em que tipo de argumento e (ii) por quem? Naturalmente, Dworkin entende pela superioridade dos argumentos de princípio. Coloca, portanto, a segunda questão nos seguintes termos: na resolução de questões que suscitam desacordos morais em sociedade, " as decisões judiciais em questões de princípio (que se diferem de políticas) ofendem qualquer teoria plausível da democracia?". ${ }^{42}$

Ora, na medida em que Dworkin entende que (i) Direito e moralidade política não estão separados, e mais, que (ii) do juiz responsável é exigido que se aplique as convicções institucionalizadas de moralidade política, em coerência com os princípios subjacentes à comunidade, não há que se falar em ofensa à democracia quando questões de direitos sejam resolvidas pelo Judiciário, porque, a partir de uma visão dworkiniana, a democracia liberal é algo que transcende as noções que envolvam apenas um ideal (meramente) majoritário. Direitos (individuais, políticos) funcionam como "trumps", como "trunfos" em face de argumentos que, porque baseados em premissas anteriores de cunho majoritário, podem muitas vezes carregar um viés utilitárioinstrumental intrínseco. ${ }^{43} \mathrm{Na}$ concepção dworkiniana de democracia, os cidadãos são iguais, tratados como iguais, e têm "igual participação nos resultados", o que significaria

42 Tradução livre para "[d]o judicial decisions on matters of principle (as distinct from policy) offend any plausible theory of democracy?" Cf. DWORKIN, 1985, p. 24.

43 Cf. DWORKIN, 1985, pp. 59, 68, 82. DWORKIN, 2005, pp. 01-37. 
muito mais que um voto de igual peso. ${ }^{44}$ A regra da maioria não tem qualquer valor por si só e em si mesma. ${ }^{45}$

É essencialmente com base nessas premissas de fundo, e em razão delas, que Dworkin sustenta que, em muitas questões sensíveis - tais como questões que envolvam relações raciais, ${ }^{46}$ por exemplo - "legisladores estão sujeitos a pressões às quais juízes não estão", razão pela qual teríamos boas razões "para supormos que juízes estão mais propensos a chegar em conclusões sensatas sobre direitos". ${ }^{47}$ É, nas palavras do próprio autor, um argumento "teorético" e, sobretudo, "institucional", ${ }^{48}$ que está - como não poderia ser diferente - intimamente ligado à sua concepção interpretativa sobre o fenômeno jurídico tal como ele é.

A Suprema Corte, goste-se ou não, é responsável por tomar importantes decisões políticas. Para Dworkin, repetimos, essas decisões devem ser de princípio; por trás disso, deve figurar, como premissa mais fundamental, a ideia de que o governo deve tratar todos os cidadãos como iguais. É nesse sentido que, quando se trata de resolver desacordos, é muitas vezes preferível que essas decisões, finais, autoritativas, ocorram não no "battleground" 49 da política, mas nas Cortes - que, tendo os juízes a responsabilidade política que lhes é exigida, tornam-se um "fórum de princípio".

44 Tradução livre para "in a genuinely democratic community each citizen participates as an equal partner, which means more than just that he has an equal vote. It means that he has an equal voice and an equal stake in the result". DWORKIN, 2011, p. 05. Cf. também DWORKIN, 2005, pp. 07-08.

45 Cf. DWORKIN, 2011, p. 348.

46 O exemplo é do autor.

47 Grifos nossos, e tradução livre para "legislators are subject to pressures that judges are not, and this must count as a reason for supposing that, at least in such cases, judges are more likely to reach sound conclusions about rights". DWORKIN, 1985, p. 25.

48 DWORKIN, 1985, p. 28.

49 "Campo de batalha", em tradução livre. 
Porque, afinal, os conflitos mais fundamentais devem, "em algum lugar", ser tratados como "questões de justiça". Nesse sentido, diz Dworkin: "não chamo a isso de religião ou profecia. Chamo a isso de Direito". ${ }^{50}$

\section{Jeremy Waldron}

Waldron e Dworkin, como vimos, compartilham de uma premissa fundamental: a de que qualquer descrição que se pretenda adequada acerca do Direito deve (ou deveria), obrigatoriamente, levar em conta seu caráter interpretativoargumentativo - o que, paradoxalmente, já invalida por si só a abordagem puramente descritiva. Como descrever um fenômeno que exige por definição o engajamento argumentativo daqueles que dele participam?

Os autores, contudo, seguem no mesmo caminho somente até certo ponto. Na leitura de Waldron - e parece inegável -, Dworkin associa a democracia a uma teoria jurídica baseada em direitos reforçados pelo Judiciário. ${ }^{51}$ Como o próprio Dworkin deixa muito claro, sua concepção de democracia é muito distinta daquelas construídas a partir do princípio majoritário. Por sua vez, Waldron é mais otimista que Dworkin com relação a esse princípio. (Ou mais pessimista com relação ao raciocínio moral dos juízes? A pergunta fica em aberto.)

Se Dworkin diz que, quando se discutem determinadas questões, legisladores podem estar sujeitos a pressões

50 Grifos nossos, em trechos livremente traduzidos de "[w]e have an institution that calls some issues from the battleground of power politics to the forum of principle. It holds out the promise that the deepest, most fundamental conflicts between individual and society will once, someplace, finally, become questions of justice. I do not call that religion or prophecy. I call it law." DWORKIN, 1985, p. 71.

51 "Ronald Dworkin [...] associates democracy with a jurisprudence of rights enforced by the judiciary". WALDRON, 2009a, pp. 675-712. 
que juízes, em tese, não estariam, Waldron oferece uma perspectiva bastante diferente: diz que, "se importantes decisões sobre questões divisivas devem ser tomadas", é mais apropriado que assim seja "em um ambiente institucional que é mais aberto - mais explícita e intencionalmente aberto - do que são as Cortes" às contribuições, aos pontos de vista, à participação da sociedade. ${ }^{52}$

Porque concordam com relação ao caráter essencialmente argumentativo-interpretativo do Direito, Waldron e Dworkin também concordam, ao menos em alguma medida, com relação à natureza do raciocínio judicial: aquilo que se faz nos Tribunais e subjaz às decisões judiciais, é verdade, não é puramente um raciocínio moral; contudo, disso não se segue que se trata de algo eminente, pura e somente jurídico, como se fosse possível uma separação completa entre as duas esferas. O raciocínio jurídico seria "uma mistura, que, em sua riqueza e textura, difere-se consideravelmente tanto de um raciocínio puramente moral" quanto de um raciocínio baseado em questões já indisputáveis como "certos positivistas ingênuos podem imaginar" . ${ }^{53}$ Só que, se Dworkin entende que esse é o melhor tipo de raciocínio, a partir do qual se deve derivar conclusões e decisões sobre direitos, Waldron alerta para o fato de que, não sendo puramente moral o raciocínio jurídico, a racionalidade jurídica (e sua responsabilidade política subjacente) envolverá, sempre, questões de respeito a textos, precedentes, institutos, questões de interpretação, de fidelidade aos elementos dos casos

52 Tradução livre para "if important 'watershed' decisions have to be made [...], it seems to me appropriate that they should be made in an institutional setting that is more open-and more explicitly and deliberately open-to societal inputs than courts are". WALDRON, 2009d, pp. 69-82.

53 Grifo nosso, e tradução livre para "[w] hat we have is a mélange of reasoning [...] which, in its richness and its texture, differs considerably from pure moral reasoning as well as from the pure version of black-letter legal reasoning that certain naive positivists might imagine". WALDRON, 2009c, pp. 02-24. 
concretos, etc. Assim, "em certas questões fundamentais de direitos", teríamos boas razões para preferirmos "o raciocínio [puramente] moral, ${ }^{54}$ ainda que de menor qualidade, nãoadulterado", não-contaminado, "dos legisladores" no lugar do "raciocínio [ainda que] de melhor qualidade mas ainda assim contaminado de material jurídico dos juízes" ${ }^{55}$

Esse desacordo entre Waldron e Dworkin, é claro, está completa e diretamente ligado à divergência fundamental sobre a melhor concepção de democracia. Se na concepção dworkiniana, de uma democracia substantiva, direitos individuais funcionam como trunfos, Waldron diz que “[n]ão podemos jogar trunfos quando discordamos com relação aos [próprios] naipes das cartas" ${ }^{56}$ Waldron, portanto, não quer negar - pelo contrário - que uma concepção adequada de democracia envolve direitos individuais, ${ }^{57}$ nem quer (necessariamente) negar que pode haver uma resposta correta com relação à objetividade dos valores subjacentes a esses direitos. Quer, sim, dizer que a última palavra do Judiciário com relação às questões que nos dividem enquanto sociedade (i) tampouco garante, por si, uma melhor proteção aos direitos, e, sobretudo, (ii) carece de legitimidade democrática. Waldron não é um cético com relação aos direitos; pelo contrário, sua defesa do Legislativo

$54 \mathrm{~N}$. de T. O que não significa, frise-se, raciocínio moral de qualidade, como se depreende a partir do restante do trecho. O ponto de Waldron é sobre a natureza da racionalidade subjacente, de um ponto de vista ontológico.

55 Tradução livre para "on certain fundamental issues of rights, we may have reason to prefer the lower-quality but unadulterated moral reasoning of legislators to the higher quality but legalistically contaminated moral reasoning of judges". WALDRON, 2009c, pp. 02-24.

56 Grifos nossos e tradução livre e adaptada para "[w]e cannot play trumps if we disagree about the suits". WALDRON, 1998, pp. 75-97.

57 Esse, inclusive, é um dos requisitos que Waldron coloca para que suas objeções com relação ao controle judicial das decisões políticas sejam considerados. Cf. WALDRON, 2009b, pp. 1346-1406. 
como instância de resolução dos desacordos passa pela ideia justamente de um, do mais valioso direito individual em uma sociedade que discorda: o direito de participação. ${ }^{58}$

O ponto é: existindo ou não uma resposta correta, havendo ou não verdades morais, haverá desacordos. E há boas razões que transcendem qualquer discussão metaética quanto à objetividade dos direitos para que tais desacordos sejam resolvidos pelo Legislativo. "No fim", diz Waldron, "são os desacordos morais", e não o subjetivismo, que servem de causa às suas preocupações com relação àquilo que chama de "moralização judicial" "E já que os realistas [morais] têm pouco a dizer sobre a resolução dos desacordos", Waldron segue, "eles têm pouco a oferecer para acalmar essas inquietações". ${ }^{59}$ Não é o caso de não termos direitos individuais, ou de que não há qualquer sentido nos argumentos que sustentam sua existência; acontece, contudo, que, seja qual for o significado dos direitos que temos, nós discordamos sobre esses significados próprios - e o Legislativo é a instância adequada para que esse desacordo encontre uma resposta institucional.

\section{O Movimento Know-Nothing no direito brasileiro}

Muito mais poderia ser dito sobre as respostas de Ronald Dworkin e Jeremy Waldron, sofisticadíssimas e com muitos méritos, cada uma à sua maneira. Não apenas legítimas, são respostas comprometidas com a democracia e com uma sociedade que valoriza os direitos individuais e coletivos; o desacordo entre ambos está essencialmente

58 Cf. WALDRON, 1999, pp. 232, 312.

59 Por todos os argumentos de Waldron nesse sentido metaético, ver o importante capítulo The Irrelevance of Moral Objectivity. Cf. WALDRON, 1999, pp. 164-187. 
na busca do melhor significado que se pode atribuir à democracia - razão pela qual os dois autores merecem profundas reverências. O ponto, contudo, é que ambos escrevem em e para um ambiente completamente diferente do nosso, não só do ponto de vista geográfico como também, e mais especialmente, do ponto de vista institucional. Podemos concordar mais com Waldron, podemos concordar mais com Dworkin; podemos sustentar uma democracia baseada em direitos individuais como trunfos em face da maioria ou uma concepção pautada no princípio majoritário da participação. Seja como for, o contexto brasileiro impõe a nós que busquemos ir ainda mais além.

Este não é um artigo de filosofia moral. Por essa razão, é possível que se pergunte por que exatamente escolhemos abrir este ensaio com as considerações de Alasdair MacIntyre sobre o estado da arte do discurso moral de nosso tempo. $\mathrm{O}$ motivo é bastante simples: o insight de MacIntyre é essencial porque nos parece aplicar-se igualmente ao discurso jurídico. Como na distopia de MacIntyre, como em seu diagnóstico acerca do discurso moral contemporâneo, também o discurso jurídico brasileiro de nosso tempo parece convencido (ou, no mínimo, condescendente) diante da ideia que não há uma objetividade autêntica naquilo que se diz no Direito. Se, para MacIntyre, o discurso moral contemporâneo pode ser caracterizado por uma miríade de enunciados que, na mesma medida em que se pretendem teorias éticas, são nada mais que ficções que servem meramente para conferir uma espécie de verniz filosófico a posturas subjetivistas, pensamos que o direito brasileiro pode ser igualmente caracterizado por um sem-número de abordagens, propostas, posturas, institutos e "métodos" que, igualmente, servem tão somente de justificativas fictícias para o decisionismo judicial. É possível ver isso a partir de diversas matrizes; de forma bem 
sustentada por Vichinkeski Teixeira e Radke, por exemplo, vê-se também a partir de fundamentos habermasianos que a discricionariedade judicial tem uma matriz eminentemente subjetivista. ${ }^{60}$ Tratemos brevemente de alguns exemplos.

Que dizer de uma série de (supostos) princípios sustentados por juízes e tribunais no Brasil? A partir das (mais que) legítimas considerações de Dworkin, uma série de argumentos retóricos, ad hoc, sem qualquer grau de institucionalidade, são invocados de forma a justificar qualquer decisão. Ora, os princípios - genuínos, autênticos - são jurídicos precisamente porque, já a priori, fazem parte do Direito; são padrões que devem ser observados por uma questão de moralidade política, ${ }^{61}$ institucionalizada, e, por isso, conduzem a argumentação e o raciocínio jurídico. No Brasil, ao contrário, "princípios" (rectius: argumentos retóricos que levam erroneamente o nome de princípio) são jargões que carecem tanto de institucionalidade quanto de sentido, porque, invocados a posteriori, apontam não a algo que faça parte do Direito, mas tão somente àquilo que o juízo tinha em mente quando decidiu o caso em questão (na maior parte das vezes, de forma discricionária; afinal, não haveria qualquer necessidade de recorrência a um princípio ad hoc no caso de uma decisão fundamentada em algo que não o juízo do intérprete que a profere). "Princípio da afetividade"; "princípio da instrumentalidade processual"; o célebre "princípio da colegialidade" ${ }^{62}$ Que tipo de "princípios" seriam esses, que nada vinculam e não carregam, nem sequer reivindicam qualquer relação com fundamentos jurídicos devidamente institucionalizados? Como no diagnóstico de MacIntyre acerca da filosofia moral, também nesse caso uma suposta

60 Cf. VICHINKESKI TEIXEIRA, RADKE, 2017.

61 DWORKIN, 1978, p. 22.

62 STRECK, 2017 b, pp. 569-564. 
linguagem técnica e específica de sua esfera de aplicação faz pouco ou nada mais que camuflar meras preferências subjetivistas.

No mesmo sentido, fenômeno similar ocorre com relação à ponderação de Robert Alexy. ${ }^{63}$ Fausto de Morais bem demonstra o modo equivocado como as lições alexyana têm sido tratadas pelo Supremo Tribunal Federal brasileiro: em 189 casos julgados em uma década, a Suprema Corte não seguiu o procedimento genuinamente propugnado pelo jurista alemão em nenhum deles. ${ }^{64}$ No Brasil, sob o nome de "ponderação", os tribunais repristinam nada além daquilo que Philipp Heck chamava, na Interessenjurisprudenz (Jurisprudência dos Interesses), de Abwägung - quequer dizer algo nas linhas de sopesamento, balanceamento ou, justamente, ponderação. Para essa escola clássica, caberia ao juiz, em sua função interpretativa, recompor os interesses em conflito que estavam presentes quando do processo de elaboração da lei e, nos casos de lacuna, proceder ao seu preenchimento a partir dessa Abwägung dos interesses que estivessem em choque nos casos que estivessem em questão. Qualquer crítica que se faça a Alexy e/ou à sua teoria é preciso fazer justiça: sua tese não envolve, jamais envolveria, esse tipo de escolha praticada no Brasil. A ponderação alexyana é o modo, sim, de resolução de conflitos jurídicos em que há colisão de princípios; contudo, esse é um complexo procedimento composto por três etapas: a adequação, necessidade e a proporcionalidade em sentido estrito. As duas primeiras se encarregam de esclarecer as possibilidades fáticas; a última, responsável pela solução das possibilidades jurídicas do conflito, recebendo do autor o nome de lei do sopesamento (ou da ponderação). A resposta obtida pela ponderação resulta numa norma de

63 Cf. STRECK, 2017a, pp. 153-158. STRECK, 2017b, pp. 78-92.

64 Cf. DE MORAIS, 2016. 
direito fundamental atribuída (zugeordnete Grundrechtnorm), que deverá ser aplicada subsuntivamente ao caso concreto, servindo para resolver também outros casos subsequentes. Repitamos: as críticas podem, devem ser feitas à teoria de Alexy; seja como for, não se trata disso aqui. O ponto é que, assim como se faz com os princípios - e, de novo, assim como se tem feito em filosofia moral, de acordo com MacIntyre -, o direito brasileiro utiliza-se de teorias que, em verdade, são tratadas de facto pelo intérprete como abstrações desprovidas de qualquer significado autêntico, que servem para fazer irromper meras atitudes, meras escolhas tão subjetivas quanto irracionais.

Talvez esses dois cenários tornam desnecessário qualquer exemplo adicional; ainda assim, é interessante mencionar ainda que o mesmo também pode ser dito sobre a leitura que parte da doutrina brasileira faz do instituto dos precedentes. ${ }^{65}$ Para esses autores ${ }^{66}$ (i) o Código de Processo Civil de 2015 aproxima o Brasil e, portanto, seu sistema de civil law, do common law, na medida em que (ii) os provimentos do art. 927 do Código são considerados, a priori, precedentes vinculantes - sob um sentido de, veja-se, "entendimentos que firmam orientações gerais obrigatórias para o futuro" ${ }^{67}$ A pergunta que surge é óbvia: podemos tratar precedentes, provimentos vinculantes, súmulas, todos esses elementos, como mecanismos prospectivos voltados, já a priori, para pré-ordenar o direito aplicável em casos futuros? O stare decisis, legítimo, do common law responde por si só, precisamente porque não funciona dessa forma ${ }^{68}$ No direito anglo-saxão, precedentes

65 Ver, principalmente, STRECK, 2018.

66 Por todos, ver BARROSO, MELLO, 2016, pp. 09-52; MARINONI, MITIDIERO, ARENHART, 2015.

67 Grifos nossos. BARROSO, 2015, pp. 160-161, 235-248.

68 Para uma (rara) leitura adequada dos precedentes, tal como realmente são, 
não são feitos; menos ainda, feitos para resolver casos futuros de antemão. ${ }^{69}$ São os tribunais subsequentes que, a partir das decisões pretéritas, identificam as circunstâncias fáticas e aplicam a ratio decidendi da decisão precedente ${ }^{70}$ - algo que, por si só, já envolve uma controvérsia que atravessa o século e divide os scholars britânicos e norte-americanos, em uma discussão complexa (tão complexa quanto solenemente ignorada pela parcela da doutrina brasileira, que pretende apropriar-se do instituto dos binding precedents sem enfrentala). Assim, a partir da ideia de "precedentes", desenvolvemse argumentos segundo as quais uma série de decisões, teses, súmulas, etc., todos esses elementos têm aplicação rígida e obrigatória por parte dos juízes e tribunais inferiores - sem, contudo, que se desenvolva uma epistemologia adequada em favor desses argumentos próprios. Uma defesa política do papel das ditas "Cortes Supremas" é diluída em um raciocínio que se pretende teorético-jurídico em favor da "segurança jurídica" (que, no contexto, não passa de uma entidade fictícia, na medida em que não se demonstra o significado que lhe é atribuído enquanto conceito).

Os exemplos, infelizmente, são inúmeros. Mas o ponto é que para além disso, e tomemos qualquer dos exemplos, o diagnóstico de MacIntyre quanto ao discurso moral contemporâneo parece-nos plenamente aplicável ao direito brasileiro. Vivemos uma espécie de emotivismo jurídico; não há - ou, melhor dizendo, a comunidade jurídica age como se não houvesse - qualquer objetividade, qualquer possibilidade de responsabilidade e fidelidade com relação ao discurso jurídico e à Teoria do Direito como tal. Repetimos aqui o diagnóstico macintyreano acerca de nossa cultura moral

na doutrina nacional, ver LOPES FILHO, AUGUSTO MAIA, 2018, em artigo publicado na RBEP.

69 Cf. TARUFFO, 2014, pp. 37-57. ELLIOTT, 1983, pp. 125-176.

70 LAMOND, 2011. 
após a declaração de indefinibilidade do bem por parte de Moore: nada mais que ações justificadas a partir de pretensas teorias éticas (mas verdadeiras ficções), que se traduzem em nada além de atitudes, de posturas, preferências subjetivas que se escondem sob as asserções de supostos princípios e pseudofundamentos. Não é isso que tem ocorrido no direito brasileiro? Com o título de "princípios", argumentos retóricos ad hoc que, carecendo até mesmo do mais mínimo grau de institucionalidade, são invocados para servir de justificação a decisões já tomadas anteriormente e, com muita frequência, sem qualquer fundamento jurídico que lhe sirva de sustentação; sob a ponderação (supostamente) alexyana, escolhas arbitrárias de "princípios" - por vezes, também colocados arbitrariamente em questão; a partir dos "precedentes", defende-se uma posição acerca do papel institucional dos Tribunais Superiores no país.

\section{Considerações finais: autonomia do Direito e teoria da decisão}

Feitas todas essas reflexões e, especialmente, a partir de todas elas, resta muito claro que, em face de nossos complexos e profundos desacordos, não basta atribuir ao Direito o papel de sua resolução em uma espécie de, em termos rawlsianos, equilíbrio reflexivo; ${ }^{71}$ não basta elencar um conjunto de princípios institucionais para resolver determinados desacordos particulares de modos particulares. Isso porque, como na esfera moral, aquilo que MacIntyre ilustra com a metáfora do Know-Nothing pode atingir também a interpretação desses princípios sobrepostos por parte das instituições responsáveis por aplica-las. Se (i) tudo é relativo, se nossas proposições são nada mais que manifestações, talvez volitivas, de nossas atitudes e emoções,

71 Cf. RAWLS, 1999, p. 18. 
e (ii) aceitamos esse cenário porque "é assim que é", corremos o risco de que também a resposta institucional do Estado, personificado pelos juízes ou legisladores, seja uma expressão de vontade emocional e nada mais que isso, sem qualquer compromisso com nada.

Vimos uma série de exemplos nos quais voluntarismos de natureza emotivista são empregados - por juízes e até pela doutrina - de forma camuflada em meio a supostas fundamentações que, sempre pela metade, acabam por se referir a teorias autênticas como mera retórica. Talvez a conclusão mais óbvia fosse a adoção de uma concepção de democracia como a de Waldron: se há um consenso emotivista nos tribunais brasileiros (que em muito se afastam dos fóruns de princípio propugnados por Dworkin), talvez, prima facie, a saída mais fácil seja defender uma redução do poder dos juízes em sede de controle de constitucionalidade e fortalecer uma espécie de soberania parlamentar. Acontece que, novamente, algumas inquietações vêm à tona: primeiro, o contexto institucional por si só. Nossa Constituição não é uma bill of rights que dispõe diretrizes gerais interpretativas. Temos uma Constituição analítica, extensa, de forma que seria impossível defender um controle de constitucionalidade reduzido (chamado por Waldron de weak judicial review), ${ }^{72}$ não-vinculante. Não só isso: todos os pontos sustentados por Waldron em favor de uma concepção majoritária de democracia, com um papel reduzido do Poder Judiciário na atribuição de sentido aos direitos individuais, não são incondicionais: ele próprio assume que essa defesa exige (i) uma sociedade compromissada com direitos, em que a maioria de seus cidadãos leva-os a sério e (ii) instituições em pleno funcionamento. ${ }^{73}$ Será que é o caso do Brasil? O simples

72 WALDRON, 2009b, pp. 1346-1406.

73 WALDRON, 2009b, pp. 1346-1406. 
fato de essa questão ser suficientemente controversa a ponto de ser impossível sua resposta nesse espaço parece razão suficiente para questionarmos se os argumentos de Waldron são todos, em seus próprios termos, aplicáveis e adequados ao nosso cenário (político, jurídico, institucional, social); à nossa democracia tal como ela é.

Nesse sentido, em uma palavra final, o que se quer dizer é que, uma vez que o Direito tem um importante papel na resolução institucional e nossos (aparentemente) intermináveis desacordos, não se pode ser complacente com um fenômeno jurídico que, tal como o discurso moral no diagnóstico de MacIntyre, aceite o predomínio de uma noção emotivista. Se os desacordos em sociedade são ceticamente tratados como um embate de atitudes e vontades irracionais, sem qualquer grau de objetividade, não pode também o Direito estar construído sobre uma série de posturas judiciais e doutrinárias que expressam nada mais que retórica voluntarista disfarçada de fundamentação jurídica.

Dworkin tem razão quando diz que qualquer concepção de democracia que se pretenda adequada e responsável deve respeitar os direitos de seus cidadãos, tratados com igual respeito por parte do Estado; tem razão quando diz que princípios devem sobrepor-se a argumentos utilitáriopragmáticos de política; acerta quando diz que o Direito é um fenômeno que não se separa da moralidade, e que o juiz responsável vai argumentar somente, e tão somente nos limites da moralidade institucionalizada. Nossas Cortes, porém, não parecem os fóruns de princípio imaginados por ele imaginados; nossos tribunais não são constituído por juízes que se aproximem de Hércules, o juiz metafórico a partir do qual Dworkin demonstra a responsabilidade subjacente ao raciocínio judicial que a integridade exige. ${ }^{74}$

74 Ver, principalmente DWORKIN, 1986, pp. 245-254. 
Waldron tem razão quando diz que, ainda que haja uma resposta correta acerca dos direitos, haverá desacordos em sociedade acerca do significado autêntico desses direitos; tem razão quando diz que, em não sendo puramente moral o raciocínio judicial, é muitas vezes preferível que as decisões sejam tomadas em um ambiente institucional livre dos limites que a responsabilidade jurídica impõe; acerta, em maior ou menos grau, quando diz que a última palavra do Judiciário, sob muitos aspectos, carece de legitimidade democrática e não garante, necessariamente, uma melhor resposta. Nossa Constituição, portanto, não é apenas uma bill of rights. Para além disso, principalmente, é plenamente possível, legítimo, e até necessário discutir se nossa democracia satisfaz as condições que Waldron impõe ao próprio argumento.

Como deve, então, o Direito funcionar de forma a resolver nossos tão profundos desacordos? É evidente que não temos uma resposta final, exatamente porque o Direito é interpretativo e qualquer tese que pretenda colocar fim à questão falha ao não levar em conta o caráter eminentemente argumentativo do fenômeno. Ainda assim, é muito importante que se diga que, qualquer que seja a concepção interpretativa adotada, nenhuma resposta satisfatória pode vir do emotivismo jurídico. Se o discurso moral com o qual expressamos nossos desacordos parte do pressuposto de que não há qualquer racionalidade ou objetividade possível, e seguimos expressando meras preferências pessoais subjetivas, nossa democracia falha na medida em que a instituição responsável por solucionar nossos conflitos - o Direito - seja ela também baseada em uma perspectiva emotivista. Se não é possível um consenso em uma sociedade dominada pelo emotivismo, se há uma rejeição à objetividade moral domina a raiz dos desacordos, a resposta, objetiva, deve vir a partir da objetividade da tradição do próprio Direito. Hermeneuticamente, é possível afirmar que há sempre um chão linguístico no qual está assentada a tradição que envolve um determinado conceito 
ou enunciado. A resposta nunca pode vir antes das perguntas; perguntas, por sua vez implicam o necessário estabelecimento de critérios a partir dos quais se pode encontrar respostas adequadas.

As respostas não vêm antes das perguntas e o Direito é um fenômeno interpretativo; não encerraríamos questões tão complexas aqui nem mesmo se quiséssemos. Ainda assim, é possível dizer que só há saída democrática a partir de um fenômeno jurídico compreendido em consonância com nossa facticidade, nossas próprias circunstâncias que definem as instituições do país. Nesse sentido, é papel da doutrina engajar-se na busca de uma teoria da decisão judicial, fiel ao Direito, em toda sua autonomia, e aos sentidos que a tradição da própria pratica impõe; uma teoria responsável, ela, sim, por estabelecer esses critérios que definem as diretrizes de uma resposta institucional adequada e democrática, a única que pode resolver nossos desacordos para além do emotivismo com o qual temos sido complacentes.

\section{Referências}

ALEXANDER, Larry. Precedent. In: PATTERSON, Dennis (ed.). A Companion to the Philosophy of Law and Legal Theory. Oxford: Blackwell, 1996, pp. 493-504.

AYER, A. J. Language, Truth and Logic. Londres: Penguin, 1990.

BAHIA, Alexandre; NUNES, Dierle. Crise da Democracia Representativa-InfidelidadePartidária e seu Reconhecimento Judicial. In: Revista Brasileira de Estudos Políticos, Belo Horizonte, n. 100, p. 57-84, jan./jun. 2010.

BALDWIN, Thomas. George Edward Moore. In: ZALTA, Edward N. (ed.) The Stanford Encyclopedia of Philosophy, Summer 2010 Edition. Stanford, Metaphysics Research Lab, 
Stanford University. <https:/ / plato.stanford.edu/archives/ sum2010/entries/moore>. Acesso em 26 nov. 2018.

BARROSO, Luís Roberto. O Controle de Constitucionalidade no Direito Brasileiro. 7. ed. Rio de Janeiro: Saraiva, 2015.

BARROSO, Luís Roberto; MELlO, Patrícia Perrone Campos; Trabalhando com uma nova lógica: a ascensão dos precedentes no direito brasileiro. Revista da AGU, Brasília, v. 15, n. 03, Editora Fórum, jul./set. 2016, pp. 09-52.

DE MORAIS, Fausto Santos. Ponderação e Arbitrariedade: a inadequada recepção de Alexy pelo STF. Salvador: Juspodivm, 2016.

DWORKIN, Ronald. A Matter of Principle. Cambridge: Harvard University Press, 1985.

Freedom's Law: The Moral Reading of the American Constitution. Oxford: Oxford University Press, 2005.

Press, 2011.

Justice for Hedgehogs. Cambridge: Belknap . Law's Empire. Londres: Belknap Press, 1986.

Harvard University Press, 1978.

Taking Rights Seriously. Cambridge:

ELLIOTT, E. Donald. INS v. Chadha: The Administrative Constitution, the Constitution, and the Legislative Veto. The Supreme Court Review, ano 1983, Chicago, University of Chicago Press, 1983, pp. 125-176.

FERREIRA NETO, Arthur Maria. Metaética e a Fundamentação do Direito. Porto Alegre: Elegantia Juris, 2015.

HARE, Richard M. The Language of Morals. Oxford: Clarendon Press, 1952.

LAMOND, Grant. Precedent and analogy in legal reasoning. In: ZALTA, Edward N. (ed.). The Stanford Encyclopedia of 
Philosophy. Spring 2016 ed. Stanford: Metaphysics Research Lab, Stanford University, 2011. Disponível em: <https:// plato.stanford.edu/archives/spr2016/entries/legal-reasprec/>. Acesso em 28 nov. 2018.

LOPES FILHO, Juraci Mourão; MAIA, Isabelly Cisne Augusto. O uso de precedentes estrangeiros e a declaração de Estado de Coisas Inconstitucionais pelo Supremo Tribunal Federal. In: Revista Brasileira de Estudos Políticos, Belo Horizonte, n. 117, pp. 219-273, jul./dez. 2018.

MACINTYRE, Alasdair. After Virtue: A Study in Moral Theory. Londres: Bloomsbury, 2007.

MARINONI, Luiz Guilherme. MITIDIERO, Daniel. ARENHART, Sérgio Cruz. O Novo Processo Civil. São Paulo: Revista dos Tribunais, 2015.

MOORE, G. E. Principia Ethica. Edição revisada, editada e introduzida por Thomas Baldwin. Cambridge: Cambridge University Press, 2002.

RAWLS, John. A Theory of Justice. Edição revisada. Cambridge: Belknap Press, 1999.

RIDGE, Michael. Moral Non-Naturalism. In: ZALTA, Edward N. (ed.) The Stanford Encyclopedia of Philosophy, Spring 2018 Edition. Stanford, Metaphysics Research Lab, Stanford University. <https:// plato.stanford.edu/archives/ spr2018/entries/moral-non-naturalism/>. Acesso em 26 nov. 2018.

STRECK, Lenio Luiz. Dicionário de Hermenêutica: quarenta temas fundamentais da Teoria do Direito à luz da Crítica Hermenêutica do Direito. Belo Horizonte: Casa do Direito, 2017a.

A diferença ontológica (entre texto e norma) como blindagem contra o relativismo no processo interpretativo: uma análise a partir de ontological turn. In: 
Revista Brasileira de Estudos Políticos, Belo Horizonte, $n$. 89, p. 121-160, jan./jun. 2004.

. Hermenêutica e Possibilidades Críticas do

Direito: Ensaio sobre a Cegueira Positivista. In: Revista Brasileira de Estudos Políticos, Belo Horizonte, n. 97, pp. 35-69, 2008.

Precedentes Judiciais e Hermenêutica: o sentido da vinculação no CPC/2015. Salvador: Juspodivm, 2018.

. Verdade e Consenso: Constituição, Hermenêutica e Teorias Discursivas. 6. ed., revista, modificada e ampliada. São Paulo: Saraiva, 2017b.

TARUFFO, Michele. Aspetti del precedente giudiziale. Criminalia: Annuario di Scienze Penalistiche, Pisa, Edizioni ETS, 2014, pp. 37-57.

VICHINKESKI TEIXEIRA, Anderson; RADKE, Rafael Wagner. Habermas e a tentativa procedimental de superação da discricionariedade judicial. In: Revista Brasileira de Estudos Políticos, Belo Horizonte, n. 115, pp. 81-108, jul./ dez. 2017.

WALDRON, Jeremy. Can There Be a Democratic Jurisprudence? Emory Law Journal, Atlanta, vol. 58, 2009a, pp. 675-712.

. The Core of the Case against Judicial Review.

The Yale Law Journal, New Haven, vol. 115, 2009b, pp. 1346-1406. . Judges as Moral Reasoners. International Journal of Constitutional Law, Nova York, n. 07, 2009c, pp. 02-24.

University Press, 1999.

Law and Disagreement. Oxford: Oxford 
. Moral Truth and Judicial Review. The American Journal of Jurisprudence, Nova York, vol. 43, 1998, pp. 75-97.

Refining the Question about Judges' Moral Capacity. International Journal of Constitutional Law, Nova York, n. 07, 2009d, pp. 69-82.

. The Rule of Law as a Theater of Debate. In: DWORKIN, Ronald; BURLEY, Justine (eds.). Dworkin and his Critics, with replies by Dworkin. Londres: Blackwell, 2004, pp. 319-336.

. Stare Decisis and the Rule of Law: A Layered Approach. Michigan Law Review, Michigan, vol. 111, n. 01, 2012, pp. 01-32.

Recebido em 05/12/18

Aprovado em 22/04/19

Lenio Luiz Streck

E-mail: lenios@globomail.com

Gilberto Morbach

E-mail: gilbertomorbach@gmail.com 
